\title{
AUTOGENOUS ARTERIOVENOUS FISTULA - A CLINICAL STUDY ON A NEW TECHNIQUE GEORGE- MARTHA TECHNIQUE
}

Anand Kumar P. G $G^{1}$

${ }_{1}^{1}$ Professor, Department of Surgery, Kannur Medical College, Anjarakandy, Kannur.

\begin{abstract}
\section{BACKGROUND}

Autologous vascular access for haemodialysis is being performed by surgeons for vascular access, which should be without early failures. The first autogenous vascular access for haemodialysis was the Brescia-Cimino Radio-Cephalic direct wrist access 1966, with a superior patency of $75 \%$ at 4 years and a failure rate in the initial phase. A venous hood is formed over the artery at the site of anastomosis. Since then the technique has not changed due to its high success rate and low complications providing vascular access in treating the haemodialysis patients. Many factors play a role in persistence of these fistulae. Development of vascular kink in the cephalic vein is one such factor resulting in reduced blood flow and difficulty in access for haemodialysis. Even though it is under reported and remains elusive in its identification should not be ignored. Here, a new technique is described to refine this technique, which helps to prevent kinking of the draining AV fistula vein.

To conceptualise and use a new technique to prevent kink in draining AV fistula vein at the site of anastomosis in Autologous Arteriovenous Fistula (AAVF) and also to study its success in preventing early failures.
\end{abstract}

\section{MATERIALS AND METHODS}

971 patients were divided into two groups. Group "A" patients were performed conventional AAVF. Group "B" patients were performed a new surgical technique to create AAVF. The new technique consisted of placing heel of the venous hood distally and the toe of the hood proximally. All the patients were followed up for 1 year and assessed clinically and on Doppler study for persistence of fistula and vascular flow.

\section{RESULTS}

Group A included 223 patients undergoing conventional method of AAVF showed a failure rate of 5.82\% at the end of first month and Group B patients undergoing the new technique described in the study showed no failure at the end of first month and both the groups were followed up for 1 year. The study was statistically significant with a $\mathrm{p}$ value of 0 .

\section{CONCLUSION}

This new refined technique named by the author as George-Martha technique was found to be effective in preventing an immediate kink in the draining vein following AAVF for dialysis patients. The procedure is simple and easy to learn and can be adopted by the surgeon.

\section{KEYWORDS}

Vascular, Arteriovenous Fistula, Haemodialysis, Chronic Renal Disease, AAVF, Kink.

HOW TO CITE THIS ARTICLE: Kumar APG. Autogenous arteriovenous fistula - a clinical study on a new technique George-Martha technique. J. Evolution Med. Dent. Sci. 2016;5(85):6345-6349, DOI: 10.14260/jemds/2016/1433

\section{BACKGROUND}

Autologous Arteriovenous Fistula (AAVF) is the common vascular access created for haemodialysis, commonly done in upper limb at wrist between Radial artery and cephalic vein creating a venous hood on Radial artery. The physicians of Bronx Veterans Administration Hospital, New York City, described the surgical AAVF for the first time in 1966 by creating AAVF at distal radial artery to cephalic vein.1,2 The international guidelines for vascular access acclaim that the AAVF should be performed whenever possible and the first operation of choice is the radio-cephalic direct access at the

Financial or Other, Competing Interest: None.

Submission 13-09-2016, Peer Review 12-10-2016,

Acceptance 18-10-2016, Published 24-10-2016.

Corresponding Author:

Dr. Anand Kumar P. G,

Professor, Department of Surgery,

Kannur Medical College,

Anjarakandy, Kannur-670612.

E-mail: anandkumarkmch@gmail.com

DOI: $10.14260 /$ jemds/2016/1433 wrist, the second type is the Brachiocephalic direct access at Antecubital fossa. ${ }^{3}$ AAVF is preferred wherever possible. Arteriovenous Fistula (AVF) with Artificial (PTEF) graft is done in situations where veins are not suitable for creating AAVF. This is in spite of the fact that when compared with AAVFs these Arteriovenous Grafts (AVGs) have higher rate of complications and decreased patency. 4 From their study, Woods JD et al recommended that appropriate measures to decrease vascular access-related morbidity among haemodialysis patients should include reversing the current trend toward increasing use of AV Grafts (AVG), particularly in patients younger than 65 years. $^{5}$ The factors and pathophysiology of vascular access failure following AVVF is poorly understood. This failure is significant, as it matters to patient who is in need of vascular access for dialysis. Failure of AAVF can be also due to diseased vessels and very small calibre vessels. Review of literature shows many correctable causes of vascular access failure and methods of diagnosing the causes and their management following AAVF. In the present study a factor causing failure of AAVF is kink in the draining cephalic vein, was shown preventable by a new technique. The present study includes of a series of 971 
patients undergoing AAVF at Kannur Medical College Dialysis unit between 2008 and 2016.

\section{MATERIALS AND METHODS}

Totally 971 patients were included in the present study of AAVF performed in the distal radial artery with cephalic vein and brachial artery and cephalic vein. During the period between Jan. 2007 and Jan. 2009, 223 patients were performed with conventional method described by MJ Brescia, ${ }^{6}$ which is heel of the venous hood is kept proximally and foot of the hood kept distally and sutured to the radial artery. This is called as Group A. During the period between July 2008 and July 2016, 748 patients were performed by George-Martha technique where the heel of the venous hood is kept distally and foot of the venous hood is kept proximally and sutured to the artery. This also includes AAVF at both wrist and elbow. This group is called Group B. Both the groups were operated upon by the same surgeon of Department of Surgery of Kannur Medical College Hospital. The study was conducted after taking prior Ethical Committee Clearance from the Institute and due informed consent was taken from the patients.

\section{Inclusion Criteria}

1. Patients with Chronic Kidney Disease undergoing haemodialysis belonging to all age groups. 2. Patients with failed AAVF at the wrist.

\section{Exclusion Criteria}

Patients with previous history of AVG.

Usually in AAVF, venous hood is created on the artery in antegrade fashion, i.e. Heel of the hood proximally and Toe of the hood distally. In George-Martha Technique the venous hood is reversed on the artery, i.e. the Heel is kept distally and the toe of the venous hood is kept proximally and sutured to the artery.

\section{Diagrammatic Comparison between Conventional and George-Martha Technique}

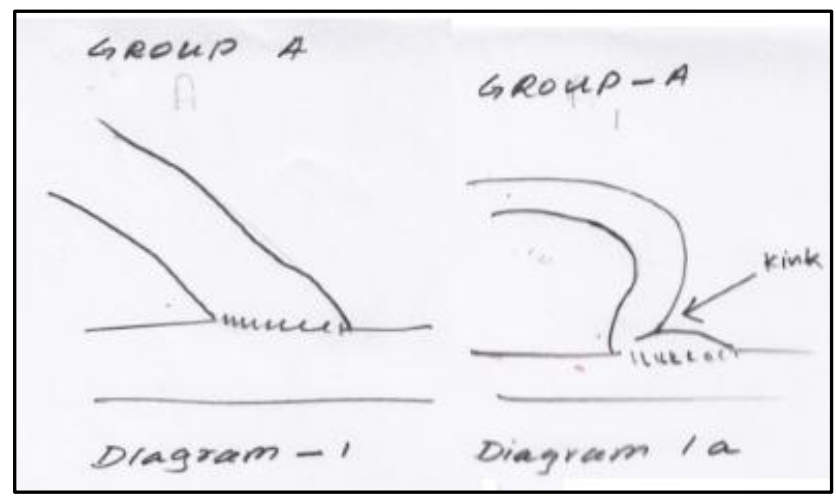

Figure 1 and 2. Showing the Group "A" AAVF

Anastomosis is made with the heel of the hood proximal and toe of the hood distal. The length of the vein should not be longer. Even if the length of the vein is little long (Even by few millimetres) when flow is established, the vein tends to fall distally and the wall of the vein forming the hood dents into the lumen causing obstruction to flow. Though in all cases it is not obvious for naked eye, it is the cause of non-functioning of the fistula (Early Failure).

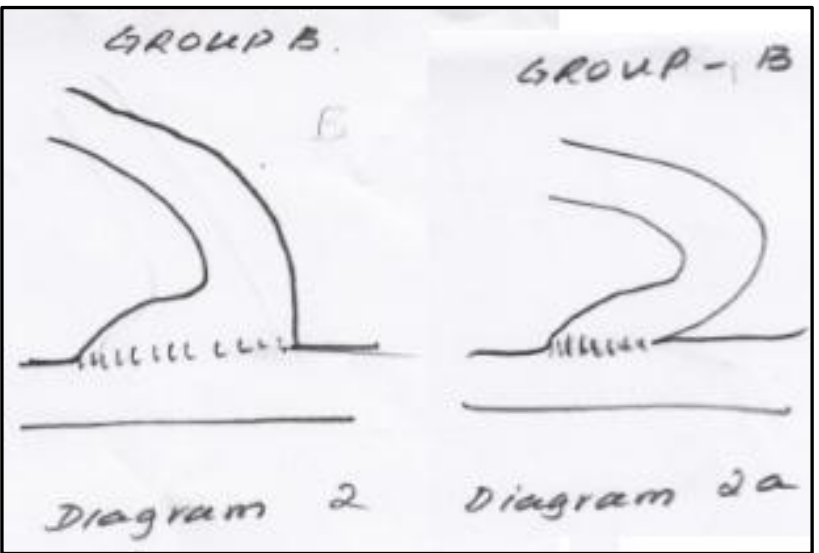

Figure 3 and 4. Showing the Group " $B$ " $A A V F$

Where anastomosis is made with heel distal and toe proximal. The extra length of the vein if present does not matter, because when the flow is established the vein falls distally and the vein wall which forms the hood is not kinked. This facilitates full expansion of the hood and better haemodynamic flow.

13 patients of Group "A" who showed a failed AAVF at the end of first month were re-operated and an intraoperative observation was made to the early cause for such failure. All the patients were followed up for 1 year following the surgery. The vascular flow is judged by clinical examination of presence of thrill, bruit and Doppler examination of the AAVF. This assessment was done at the end of 1 st $, 5^{\text {th }}, 9^{\text {th }}$ and $12^{\text {th }}$ month. Presence of reduction in the vascular flow or development of complications is noted and recorded. All the data was analysed with standard statistical methods.

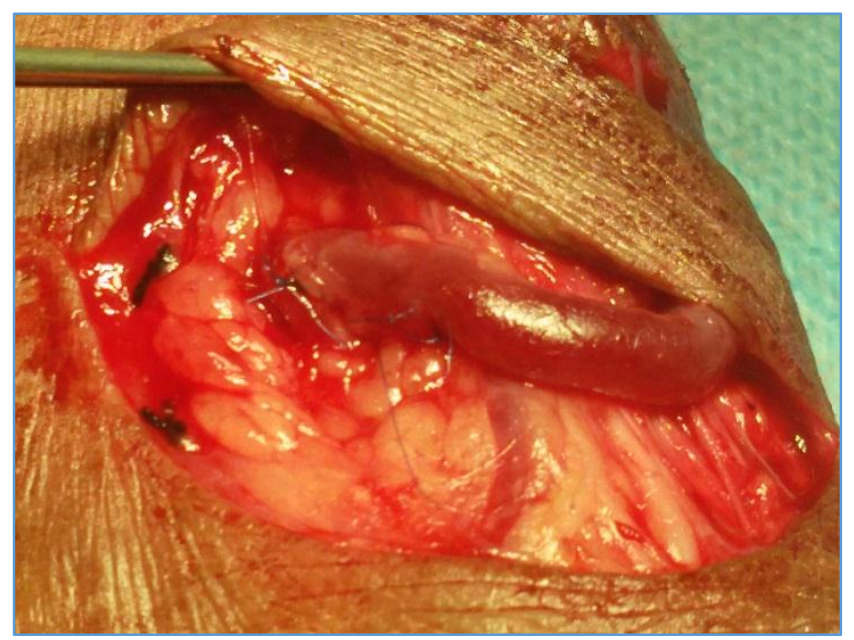

Figure 5. AAVF at Left Wrist

\section{RESULTS}

971 patients were performed AAVFs in Kannur Medical College and Hospital, Anjarakandy, Kerala, in Surgery Department referred from Dialysis Unit of our hospital and nearby hospitals. In Group A during the period between Jan 2007 and Jan 2009, 223 patients were performed with conventional method described by MJ Brescia6 that is heel of the venous hood is kept proximally and foot of the hood kept distally and sutured to the radial artery. In Group B during the period between July 2008 and July 2016, 748 patients were performed by George-Martha technique, that is heel of the venous hood is kept distally and foot of the venous hood is kept 
proximally and sutured to the artery. In the Group A, the male patients were 187 (83.85\%) and females were 36 (16.14\%) with an F:M ratio of 1:5.19. The patient's age was ranging from 25 years to above 85 years with a mean age of $46.23 \pm 1$. The youngest patient was aged 25 years and the oldest one aged 79 years. $47.08 \%$ (105) of the patients belonged to the age group of 46 to 55 years followed by $23.76 \%$ patients to 56 to 65 years and $19.73 \%$ to the age group of 66 to $75 \%$ (Table 1 ).

\begin{tabular}{|c|c|c|c|c|c|}
\hline $\begin{array}{c}\text { Sl. } \\
\text { No. }\end{array}$ & $\begin{array}{c}\text { Age Group } \\
\text { in Yrs. }\end{array}$ & Males & Females & Total & \% \\
\hline 1 & 25 to 35 & 03 & 01 & 04 & 1.79 \\
\hline 2 & 36 to 45 & 09 & 03 & 12 & 5.38 \\
\hline 3 & 46 to 55 & 94 & 11 & 105 & 47.08 \\
\hline 4 & 56 to 65 & 45 & 08 & 53 & 23.76 \\
\hline 5 & 66 to 75 & 37 & 07 & 44 & 19.73 \\
\hline 6 & 76 to 85 & 35 & 06 & 41 & 18.38 \\
\hline \multicolumn{7}{|c|}{ Table 1. Showing the Age Incidence } \\
and Sex Incidence, Group A (n= 223) \\
\hline
\end{tabular}

During the surgery the diameter of the vein was assessed by conventional method showed that $74.88 \%$ of the patients had a diameter of 3 to $4 \mathrm{~mm}$ followed by $2.5 \mathrm{~mm}$ to $3.0 \mathrm{~mm}$ in $14.34 \%$ and 4 to $6 \mathrm{~mm}$ in $10.76 \%$ (Table 2).

\begin{tabular}{|c|c|c|c|}
\hline Sl. No. & Vein Size & Number of Patients & \% \\
\hline 1 & 2.5 to $3 \mathrm{~mm}$ & 32 & $14.34 \%$ \\
\hline 2 & 3 to $4 \mathrm{~mm}$ & 167 & $74.88 \%$ \\
\hline 3 & 4 to $6 \mathrm{~mm}$ & 24 & $10.76 \%$ \\
\hline \multicolumn{4}{|c|}{ Table 2. Showing Vein Size } \\
(Diameter in mm), Group A (n = 223)
\end{tabular}

Among the 223 patients, $69.95 \%$ (156) of the patients had undergone AAVF procedure elsewhere and were referred to this department for revision and developing vascular access (Table 3).

\begin{tabular}{|c|c|c|c|c|}
\hline $\begin{array}{c}\text { Sl. } \\
\text { No. }\end{array}$ & $\begin{array}{c}\text { Secondary } \\
\text { AAVF }\end{array}$ & \% & $\begin{array}{c}\text { Primary } \\
\text { AAVF }\end{array}$ & $\%$ \\
\hline 1 & 156 & $69.95 \%$ & 67 & $31.04 \%$ \\
\hline \multicolumn{4}{|c|}{ Table 3. Showing the Primary and } \\
Secondary AAVF in Group A (n= 223) \\
\hline
\end{tabular}

Both the group A and B patients were followed up at the end of $1^{\text {st }}, 5^{\text {th }}, 9^{\text {th }}$ and $12^{\text {th }}$ month and presence of palpatory thrill, venous accessibility for dialysis, bruit on Doppler and effect of fistula on CVS compatibility were assessed; 13 patients out of 223 belonging to Group A showed failure in AAVF function after 1 month. This accounted to $5.82 \%$ of the 223 patients, (Table 4). Average time taken for maturation of the AAVF in the group was 4 weeks. The 13 patients who showed failure in the AAVF were re-operated and a venous kink was found obstructing the vascular flow immediately distal to the anastomosis.

\begin{tabular}{|c|c|c|c|c|c|c|c|c|}
\hline Observation & \multicolumn{2}{|c|}{ After 1 Month } & \multicolumn{2}{c|}{ After 5 Months } & \multicolumn{2}{c|}{ After 9 Months } & \multicolumn{2}{c|}{ After 12 Months } \\
\hline Thrill & Good & Feeble & Good & Feeble & Good & Feeble & Good & Feeble \\
\hline & 210 & 13 & 209 & 14 & 205 & 18 & 201 & 22 \\
\hline Venous Canulation & Comfortable & Difficulty & Comfortable & Difficulty & Comfortable & Difficulty & & \\
\hline & 210 & 13 & 213 & 10 & 210 & 13 & 210 & 13 \\
\hline Bruit on Doppler & Loud & Feeble & Loud & Feeble & Loud & Feeble & Loud & Feeble \\
\hline & 210 & 13 & 208 & 15 & 206 & 17 & 206 & 17 \\
\hline Effect on CVS & Compatible & Incompatible & Compatible & Incompatible & Compatible & Incompatible & Compatible Incompatible \\
\hline \multicolumn{7}{|c|}{ Table 4. Showing the Presence of Vascular Flow by Different Parameters, $\boldsymbol{n}=\mathbf{2 2 3}$} \\
\hline
\end{tabular}

In the Group B, the male patients were 554 (74.06\%) and females were $194(26.84 \%)$ with a F:M ratio of $1: 2.855$. The patient's age was ranging from 25 years to above 85 years with a mean age of $52.09 \pm 2.1$. The youngest patient was aged 29 years and the oldest one aged 74 years. $47.08 \%$ (105) of the patients belonged to the age group of 46 to 55 years followed by $23.76 \%$ patients to 56 to 65 years and $19.73 \%$ to the age group of 66 to $75 \%$ (Table 5).

\begin{tabular}{|c|c|c|c|c|c|}
\hline $\begin{array}{c}\text { Sl. } \\
\text { No. }\end{array}$ & $\begin{array}{c}\text { Age } \\
\text { Group } \\
\text { in Yrs. }\end{array}$ & $\begin{array}{c}\text { Males- } \\
\mathbf{5 5 4}\end{array}$ & $\begin{array}{c}\text { Females- } \\
\mathbf{1 9 4}\end{array}$ & $\begin{array}{c}\text { Total- } \\
\mathbf{7 4 8}\end{array}$ & \% \\
\hline 1 & 25 to 35 & 47 & 16 & 63 & 8.42 \\
\hline 2 & 36 to 45 & 69 & 44 & 113 & 15.10 \\
\hline 3 & 46 to 55 & 78 & 32 & 110 & 14.70 \\
\hline 4 & 56 to 65 & 236 & 65 & 301 & 40.24 \\
\hline 5 & 66 to 75 & 55 & 14 & 69 & 9.22 \\
\hline 6 & 76 to 85 & 69 & 23 & 92 & 12.29 \\
\hline \multicolumn{6}{|c|}{ Table 5: Showing the Age Incidence } \\
and Sex Incidence, in Group B (n= 748) \\
\hline
\end{tabular}

During the surgery, the diameter of the vein was assessed by conventional method showed that $64.43 \%$ of the patients had a diameter of 3 to $4 \mathrm{~mm}$ followed by $2.5 \mathrm{~mm}$ to $3.0 \mathrm{~mm}$ in $15.37 \%$ and 4 to $6 \mathrm{~mm}$ in $20.18 \%$ (Table 6).

\begin{tabular}{|c|c|c|c|}
\hline $\begin{array}{c}\text { Sl. } \\
\text { No. }\end{array}$ & $\begin{array}{c}\text { Vein } \\
\text { Size }\end{array}$ & $\begin{array}{c}\text { Number of } \\
\text { Patients }\end{array}$ & \% \\
\hline 1 & 2.5 to $3 \mathrm{~mm}$ & 115 & $15.37 \%$ \\
\hline 2 & 3 to $4 \mathrm{~mm}$ & 482 & $64.43 \%$ \\
\hline 3 & 4 to $6 \mathrm{~mm}$ & 151 & $20.18 \%$ \\
\hline \multicolumn{3}{|c|}{ Table 6. Showing Vein Size } \\
(Diameter in mm), Group B (n= 748)
\end{tabular}

Among the 748 patients $73.03 \%$ (547) of the patients had undergone AAVF procedure elsewhere and were referred to this department for revision and developing vascular access (Table 7).

\begin{tabular}{|c|c|c|c|c|}
\hline $\begin{array}{c}\text { Sl. } \\
\text { No. }\end{array}$ & $\begin{array}{c}\text { Secondary } \\
\text { AAVF }\end{array}$ & \% & $\begin{array}{c}\text { Primary } \\
\text { AAVF }\end{array}$ & \% \\
\hline 1 & 547 & $73.03 \%$ & 201 & $26.87 \%$ \\
\hline \multicolumn{4}{|c|}{ Table 7. Showing Vein Size } \\
(Diameter in mm), in Group B (n= 748)
\end{tabular}




\begin{tabular}{|c|c|c|c|c|c|c|c|c|}
\hline Observation & \multicolumn{2}{|c|}{ After 1 Month } & After 5 Months & \multicolumn{2}{c|}{ After 9 Months } & After 12 Months \\
\hline Thrill & Good & Feeble & Good & Feeble & Good & Feeble & Good & Feeble \\
\hline & 748 & 00 & 748 & 00 & 748 & 03 & 748 & 00 \\
\hline Venous Canulation & Comfortable & Difficulty & Comfortable & Difficulty & Comfortable & Difficulty & & \\
\hline & 748 & 00 & 748 & 00 & 748 & 00 & 748 & 00 \\
\hline Bruit on Doppler & Loud & Feeble & Loud & Feeble & Loud & Feeble & Loud & Feeble \\
\hline & 748 & 00 & 748 & 00 & 748 & 00 & 748 & 00 \\
\hline Effect on CVS & Compatible & Incompatible & Compatible & Incompatible & Compatible & Incompatible & \\
\hline \multicolumn{7}{|c|}{ Table 8. Showing the Presence of Vascular Flow by Different Parameters, Group B (n= 748) } \\
\hline
\end{tabular}

Followup of Group B patients at the end of 1 st $5^{\text {th }}$, $9^{\text {th }}$ and $12^{\text {th }}$ month for assessing the presence of palpatory thrill, venous accessibility for dialysis, bruit on Doppler and effect of fistula on CVS compatibility. There was no failure of AAVF in all the 748 patients. There was $0 \%$ failure of AAVF (Table 8). Average time taken for maturation of the AAVF in this group also was 4 weeks. Comparing the results of both Group A and B using Fisher exact test statistics showed a statistical significance with a $\mathrm{p}$ value 0 (Taking $\mathrm{p}$ value as significant at $0.05)$.

\section{DISCUSSION}

From the time of the first description of Autologous Arteriovenous Fistula (AAVF) in 1966 for Haemodialysis 7 decades ago, vascular access has remained the mainstay of chronic haemodialysis. It is commonly done in upper limb at wrist between radial artery and cephalic vein, creating a venous hood on Radial artery. Next common site is at Left antecubital fossa between veins of the region and Brachial artery. Venous outflow obstruction is the most common at the site of anastomosis in a failing graft. The factors and pathophysiology of vascular access failure following AVVF is poorly understood. Late failures seem to be related to intimal hyperplasia in the native vessel downstream from the anastomosis. The stimulation of local growth factors by needle puncture may also play a role. 7 The present study focuses on the failures of early AAVF failures.

To assess the access of venous adequacy, careful physical examination, laboratory evaluation and ultimately angiography should be undertaken. Measuring the recirculation and venous pressure are commonly used to screen for access dysfunction. Such appropriate measures will lower the incidence of graft loss in dialysis units. Immediate failure, non-functioning of fistula, obstruction to flow; though it is significant is not reported accordingly. The incidence can be between $8-10 \% .^{7}$ The early failure is significant, as it matters to patient who is in need of vascular access for dialysis. Early failure of AAVF can be also due to diseased vessels and very small calibre vessels. Treatment of late failure is usually either angioplasty or surgery with some centres having success with thrombolytic therapy. New techniques such as atherectomy and stent placement may prove to be beneficial, but this requires further study. ${ }^{7}$ In their study of the treatment of vascular access graft dysfunction, Beathard GA ${ }^{8}$ found that long-term patency may be better when venous stenosis is surgically revised; however, Percutaneous Transluminal Angioplasty (PTA) has a number of advantages, especially the preservation of potential vascular access sites. ${ }^{8}$ Though the conventional AAVF described by Brescia MJ6 in 1966 offered a superior patency of $75 \%$ at 4 years, yet it had a higher rate of early failure where a venous hood is formed over the artery at the site of anastomosis. Among the many factors development of kink in the cephalic vein at the site of the anastomosis is one such factor resulting in reduced flow and failure of the anastomosis. In the present study of Group A patients, early failure is noted in $5.82 \%$ of the 223 patients. This was confirmed intraoperatively at the time of revision. In the present new George-Martha technique, the chances of early failure due to kink forming in the cephalic vein is totally prevented. It resulted in $0 \%$ failure both in the early phase and at the end of $12^{\text {th }}$ month review of the AAVF. An AVVF which is never usable is defined as a primary AAVF failure or when it fails within the first three months of its use and remains a major problem. Some fistulas develop correctable problems and once these problems are addressed a high success rate can be expected. ${ }^{9}$ Ferring $M$ et al concluded from their study that a new AAVF with a thrill or a vein diameter $>5 \mathrm{~mm}$ is likely to be used for dialysis after one month. An AAVF not meeting these criteria has an increased risk of failure and further investigations may be required. ${ }^{10}$ Several studies indicate that about $30 \%$ of hospitalisations are caused by the constriction and complications of vascular access. ${ }^{11}$ Both artery and vein undergo marked changes in haemodynamic forces following creation of an AAVF resulting in vascular remodelling. Blood flow increases to a level that provides an adequate delivery to the dialysis machine; the vessel increases in diameter to accommodate canulation and the vessel wall thickens to permit repeated canulation. The endpoint of this process is referred to as AV fistula maturation. ${ }^{12}$ It is also affected by patient-specific factors that determine its accessibility for canulation, such as position on the patient's extremity and fistula depth among others. P Yates and A Mahmood have shown in their study by rotating the vein through $90^{\circ}$ from the 'as it lies' position, prior to anastomosis, heel to toe length disparities are minimised, thereby avoiding kinking of the draining vein and maintaining flow and patency. ${ }^{13}$

In AAVF, Venous Hood is made on the artery nearby. Venous hood has two components Heel and Foot. Usually, the heel of the hood is kept proximal and foot of the hood is kept distal. It is a simple surgery. Immediate failure may be due to non-functioning of fistula or obstruction to the blood flow. It is not reported, though it is significantly common. In the new technique - George-Martha Technique, the immediate failure due to haemodynamic obstruction is nil as observed in the present study. In the present study, the failure rates at the end of first month following AAVF in Group A and B were compared using Fisher Exact Test Calculator to derive the $p$ value. The test showed $p$ value as 0 (With $p$ value taken significant at 0.05). George-Martha technique used in Group B patients as a modification to the conventional method 
described by Brescia MJ ${ }^{6}$ used in the Group A patients were compared with need of a procedure with the least failure rate in the early stage. This is of paramount importance to provide superior healthcare to the dialysis patients. A simple modification such as reversing the ends of the venous hood of anastomosis between the artery and cephalic vein as described in the study will be useful to millions of dialysis patients.

\section{CONCLUSION}

In the new technique - George-Martha Technique, the immediate failure due to haemodynamic obstruction is significantly reduced. Technical failure rate is nil and has superior haemodynamic performance. When the toe is sutured proximally and heel distally immediate failure is $0 \%$, whereas immediate failure in conventional method in this study also showed $5.82 \%$. The factor causing the failure was the venous kink near the anastomosis. The study is statistically significant with $\mathrm{p}$ value 0 .

\section{ACKNOWLEDGEMENTS}

I, Dr. P. G. Anand Kumar, the author dedicates the new fistula technique described in the name of my parents Mr. George and Mrs. Martha who inspired me to become a doctor of medicine.

\section{REFERENCES}

1. Mishler R. Autologous arteriovenous fistula creation by nephrologists. Adv Chronic Kidney Dis 2009;16(5):321-8.

2. Rutherford RB. Vascular access for haemodialysis. Chapter 117. Vascular surgery. $6^{\text {th }}$ edn. Philadelphia: WB Saunders 2005:1671.

3. Szeberin Z, Bíró G, Sótonyi P, et al. Role of autologous antebrachial arteriovenous fistula for vascular access in hemodialysis. Magy Seb 2006;59(6):421-8.
4. Bazan HA, Schanzer H. Transposition of the brachial vein: a new source for autologous arteriovenous fistulas. J Vasc Surg 2004;40(1):184-6.

5. Woods JD, Turenne MN, Strawderman RL, et al. Vascular access survival among incident hemodialysis patients in the United States. Am J Kidney Dis 1997;30(1):50-7.

6. Brescia MJ, Cimino JE, Appel K, et al. Chronic hemodialysis using venipuncture and a surgically created arteriovenous fistula. N Engl J Med 1966;275(20): 1089-92.

7. Porile JL, Richter M. Preservation of vascular access. J Am Soc Nephrol 1993;4(4):997-1003.

8. Beathard GA. Primary failure of the hemodialysis arteriovenous fistula. Internet Journal, Up To Date by Wolters Kluwer 2016.

http://www.uptodate.com/contents/primary-failure-ofthe-hemodialysis-arteriovenous-fistula.

9. Ferring M, Henderson J, Wilmink T. Accuracy of early postoperative clinical and ultrasound examination of arteriovenous fistulae to predict dialysis use. J Vasc Access 2014;15(4):291-7.

10. Stoic R. Most important chronic complications of arteriovenous fistulas for hemodialysis. Med Princ Pract 2013;22(3):220-8.

11. Malovrh M. Postoperative assessment of vascular access. J Vasc Access 2014;15(Suppl 7):S10-4.

12. Donnelly SM, Marticorena RM. When is a new fistula mature? The emerging science of fistula cannulation. Semin Nephrol 2012;32(6):564-71.

13. Yates $\mathrm{P}$, Mahmood A. External rotation of the draining vein improves flow in arteriovenous fistulas. Ann R Coll Surg Engl 2011;93(8):647. 